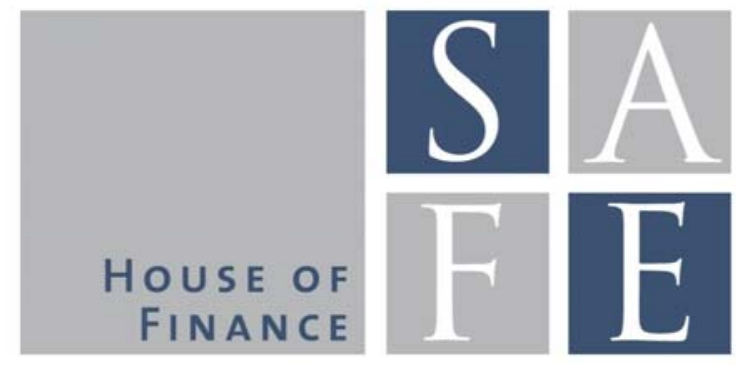

WORKING PAPER SERIES

Giuliano Curatola

\title{
Optimal Consumption and Portfolio Choice with Loss Aversion
}

SAFE Working Paper No. 130

SAFE I Sustainable Architecture for Finance in Europe A cooperation of the Center for Financial Studies and Goethe University Frankfurt 


\section{Non-Technical Summary}

In their seminal paper, Kahneman and Tversky (1979) suggest that investors are more sensitive to losses than gains and that they tend to be risk seeking after losses and risk averse after gains, rather than purely risk-averse as postulated by the classical portfolio theory. Since then many researcher have incorporated loss aversion into the theory of portfolio and studied its implications for the choice of risky assets. This literature typically applies the idea of loss aversion to the return of risky assets or to fluctuations of financial wealth, around a certain reference point. However in their seminal paper, Kahneman and Tversky argue that loss aversion is a general mental framework that can be applied to any kind of choice whose outcomes can be coded in terms of gains and losses, and not only to stock returns. Motivated by this observation, I analyse the portfolio problem of an investor who is loss averse over consumption relative to a time-varying reference level. At any point in time the investor decides how to allocate wealth between consumption, risk-free and risky assets. In addition, the reference level of consumption evolves over time and is given by a weighted average of past and current consumption.

I show that loss aversion changes the traditional consumption smoothing behavior. The loss averse agent smooths consumption only in good time (i.e., when the consumption good is cheap) and reduces consumption to the subsistence level in bad times (i.e., when the consumption good is expensive). The particular nature of the optimal consumption strategy implies that the investor's optimal portfolio has two components: a standard mean variance component and a gambling portfolio consisting of aggressive investments in stocks. The weight assigned to these two portfolios is time varying. In good times, the loss averse investor wishes to maximize the probability that his/her consumption stays above the reference level and the weight assigned to the mean variance portfolio increases. In bad times, the consumption smoothing strategy is abandoned and the investor opts for a gambling for resurrection strategy, thus rebalancing his/her portfolio toward risky assets.

This consumption-investment strategy differs from what suggested by the traditional portfolio theory and is consistent with several recent stylized facts about investors' behaviour, such as the pro-cyclical behavior of consumption smoothing, or the tendency of many individual investors to increase their equity position during the recent financial crisis. 


\title{
Optimal Consumption and Portfolio Choice with Loss Aversion
}

\author{
Giuliano Curatola*
}

Goethe Universität Frankfurt

March 16, 2016

\begin{abstract}
This paper analyses the consumption-investment problem of a loss averse investor equipped with s-shaped utility over consumption relative to a time-varying reference level. Optimal consumption exceeds the reference level in good times and descend to the subsistence level in bad times. Accordingly, the optimal portfolio is dominated by a mean-variance component in good times and rebalanced more aggressively toward stocks in bad times. This consumption-investment strategy contrasts with customary portfolio theory and is consistent with several recent stylized facts about investors' behaviour. I also analyse the joint effect of loss aversion and persistence of the reference level on optimal choices. Finally, the strategy of the loss averse investor outperforms the conventional Merton-style strategies in bad times, but tend to be dominated by the conventional strategies in good times.
\end{abstract}

Keywords: Loss-aversion, Habit-formation, Consumption-portfolio choice.

JEL Classification Numbers: G11; G12.

${ }^{*}$ I would like to thank Harjoat Bhamra, Stefano Colonnello, Jerome Detemple, Enrico De Giorgi, Pierre Collin-Dufresne, Rüdiger Fahlenbrach, Damir Filipovic, Alessandro Gioffré, Loriano Mancini, Michael Hasler, Ngoc Giang Hoang, Julien Hugonnier, Roberto Marfé, Marco Pagano, Giovanni Walter Puopolo, Claudia Ravanelli, Christian Reichlin and Marcel Rindisbacher for insightful and helpful discussions. All participants to the 10th Swiss Doctoral Workshop in Finance, (Gerzensee, Switzerland) are also greatly acknowledged. An early version of this paper circulated under the title "Optimal Stock Allocation under Loss Aversion in Consumption". The support from the Research Center SAFE, funded by the State of Hessen initiative for research LOEWE is greatly appreciated.

Author's complete address: Research Center SAFE, Goethe-University Frankfurt am Main, Campus Westend, Theodor-W.-Adorno-Platz 3, D-60323 Frankfurt am Main, Tel. +49 (0)69 798 30096, e-mail: curatola@safe.uni-frankfurt.de 


\section{Introduction}

The classical theory of portfolio choice assumes that investors are equipped with concave utility function which corresponds to the notion of risk aversion. Starting from the seminal work of Merton (1969), who derives the optimal portfolio of an investor with power utility when the investment opportunity set is constant, the portfolio theory of risk-averse investors has been extended in many directions: time-varying investment opportunity set, non-standard utility functions, different forms of learning and transaction costs. However, Kahneman and Tversky $(1979,1991,1992)$ show that the notion of risk aversion is often inconsistent with observed investors' choices. More precisely, investors seem to be more sensitive to losses than gains (loss aversion), risk-averse over gains and risk seeking over losses (risk seeking behaviour), rather than purely risk-averse as postulated by the classical portfolio theory. Moreover, investors tend to evaluate uncertain events using subjective probabilities rather than true probabilities (probability distortion). Loss aversion and risk seeking behaviour, that are analysed in this paper, are mathematically represented by the asymmetric s-shaped utility function, convex in the domain of losses and concave in the domain of gains.

Several papers show that loss aversion is not only economically plausible but also important for explaining many features of financial markets: Odean (1998) shows that loss aversion is able to explain the disposition effect; Benartzi and Thaler (1995) and Barberis et al. (2001) find that loss aversion offers an explanation for the equity premium puzzle; Dimmock and Kouwenberg (2010) find that loss aversion explains the observed pattern of investors' portfolios. Nonetheless, while the portfolio choice of risk-averse investors has been widely analysed, a comprehensive theory of portfolio for loss averse investors is still to be developed. A number of recent papers improve our understanding of this topic. The general continuous-time portfolio problem of an investor who maximizes cumulative prospect theory utility function (loss aversion, risk seeking behaviour and probability distortion) of final wealth is studied by Jin and Zhou (2008). Reichlin (2013) analyses the problem of maximizing non-concave utility of final wealth and provides the conditions under which the optimization problem can be solved by the concavification 
method. The portfolio problem of an investor equipped with s-shaped utility over final wealth is analysed by Berkelaar et al. (2004). Hens and Vlcek (2011) study the relation between loss aversion and the disposition effect. Fortina and Hlouskovaa (2011) examine the investment strategy of linear loss averse investors for different dependence structure of assets returns, namely, Gaussian copula and Clayton copula. Frühwirth and Mikula (2008) study the saving plans of loss averse investors. Gomes (2005) solves the investment problem of a loss averse investor in a model with two states of the world and studies the implications of loss aversion for the trading volume. However, our knowledge about the portfolio theory of loss averse investors is still fragmented and very little is known about loss aversion in consumption.

There are several reasons why I choose to study the case of loss aversion over consumption rather than loss aversion over final wealth. 1) As suggested by Wachter (2002) and Yogo (2008), the case of inter-temporal consumption is more in line with the notion of economic risk than the case of terminal wealth because investors trade on the financial market to hedge against the effect of economic uncertainty on consumption. 2) Curatola (2015) shows that loss aversion over inter-temporal consumption is able to reproduce, simultaneously, the observed upward sloping term structure of interest rates and the downward sloping term structure of equity. 3) The case of utility of consumption gives the possibility to model the reference level process in a way consistent with the literature of habit formation. Recently, there has been an increasing interest for optimal consumption and portfolio of investors with habit formation in preferences. However this literature typically assumes the so called "addictive property of habits", that is, the optimal consumption never falls below the reference level. Instead, with loss aversion, the optimal consumption descends below the reference level when economic conditions deteriorate. Arguably, this property is more consistent with the low consumption rate observed during the recent economic crises. 4) In their seminal paper, Kahneman and Tversky (1979) argue that loss aversion is a general mental framework that can be applied to any kind of choice whose outcomes can be coded in terms of gains and losses, and not only to lotteries that involve monetary outcomes (the typical example is the return of 
risky assets) as customary in the literature on loss aversion. Despite these considerations, the implications of loss aversion in consumption for consumption and portfolio choices are still unclear. Point 1-4 also summarize the main departures of my paper from Berkelaar et al. (2004).

In this paper I try to fill the gap in the literature by analysing the continuous-time portfolio problem of an investor equipped with s-shaped utility of consumption relative to a time-varying reference level. At any point in time the investor decides how to allocate wealth between consumption, risk-free and risky assets. Under the assumption of complete markets, the consumption-investment problem of the loss averse investor is solved analytically. The optimal consumption of the loss averse investor resembles the pay-off a portfolio that comprises a zero-coupon bond and a binary option written on the stateprice density. The zero coupon bond ensures that consumption does not descend below the minimum subsistence level. When the state-price density is below a given threshold (i.e., in good times), the binary option yields a positive pay-off that enables the investor to consume not only above his/her subsistence level but also above his/her time-varying reference level. In other words, loss averse investors smooth consumption only in good times (i.e. when the price of consumption good is low) and reduce consumption to the subsistence level in bad times (i.e. when consumption is expensive). As a result, the optimal wealth of the loss averse investor can be expressed as a portfolio of zero-coupon bonds binary options with different maturities.

The binary nature of consumption implies that the investor's optimal portfolio has two components. The first component is the standard mean-variance portfolio. The second component is a gambling portfolio consisting of aggressive investments in stocks. The weight assigned to the two components changes over time depending on the investor's consumption needs. In good times, the loss averse investor desires to smooth consumption and, thus, the optimal portfolio is dominated by the mean-variance component that guarantees that the fraction of wealth invested in bonds is sufficient to ensure that consumption remains above the reference level. In bad times, the consumption-smoothing strategy is abandoned and the optimal portfolio is rebalanced toward stocks in order to 
maximize the probability that future consumption exceeds the reference level. These results fit well with some recent findings of investors' behaviour. For instance, Hoffmann and Scherbakova-Stewen (2011) find that the consumption smoothing of US households increases in good times and decreases in bad times. Recently, Dorn and Weber (2013) show that many individual investors reacted to the financial crisis by increasing their equity positions. This finding is difficult to rationalize in a model with risk averse agents, but is consistent with the optimal strategy of loss averse investors characterized by risk seeking behaviour in bad times.

History dependence in the reference level of consumption has an important and nontrivial effect on the investor's portfolio policy. Past consumption gains/losses are linked to the current reference level and, thus, determine the investor's willingness to take on risk. When past consumption is high as compared to the reference level, an increase in the importance of past consumption reduces risk aversion in good times and decreases risk taking incentives in bad times. As a result, the loss averse investor increases the fraction of wealth invested in stocks (bonds) in good (bad) times.

Finally, I find that loss aversion has a clear effect on the performance of portfolio. In good times, the loss averse investor implements a conservative investment strategy in order to ensure that consumption stays above the reference level. This strategy requires higher investments in bonds than, for instance, the investor with CRRA utility and depresses portfolio performance because bonds pay, on average, less than stocks. However, in bad times, the loss averse investor reduces consumption to the minimum subsistence level and invests more aggressively in stocks. As a result, the portfolio's performance increases as compared with the CRRA investor.

The rest of the paper is organized as follow: Section 2 presents the framework of the optimization problem, the financial market and the investor' utility function. Section 3 shows the optimal consumption-portfolio rules. In Section 4 I discuss the implications of loss aversion and habit formation for consumption and portfolios. Section 5 concludes. 


\section{The investor's problem}

The economy The economy has a finite time horizon $T$. The uncertainty is represented by a filtered probability space $\left(\Omega, \mathcal{F},\left(\mathcal{F}_{t}\right), \mathbb{P}\right)$ on which I define a $d$-dimensional Brownian motion $B(t)=\left[B_{1}(t), B_{2}(t), \ldots B_{d}(t)\right]^{\prime}$. Consider a continuous-time financial market endowed with $d$ risky assets (stocks), indexed by $i=1,2 \ldots, d$, and a risk-free asset (bond). The investor can trade without transaction costs. The price of the risk free asset is denoted by $S_{0}(t)$ and evolves as

$$
\frac{d S_{0}(t)}{S_{0}(t)}=r(t) d t
$$

where $r(t)$ is the instantaneous risk-less interest rate. The price of the stock $i$ follows an Ito process of the form

$$
\frac{d S_{i}(t)}{S_{i}(t)}=\mu_{i}(t) d t+\sum_{j=1}^{d} \sigma_{i j}(t) d B_{j}(t)
$$

where $\mu_{i}$ is the expected return and $\left\{\sigma_{i j}\right\}_{j=1, \ldots, d}$ represents the set of volatility coefficients of stock $i$. Assume that $r, \mu=\left[\mu_{1}, \ldots, \mu_{d}\right]$ and $\sigma=\left\{\sigma_{i j}\right\}_{1 \leq i, j \leq d}$ are bounded and $\mathcal{F}$ adapted and that $\sigma$ is an invertible and bounded matrix. Under these assumptions, the price of risk process

$$
\theta=\sigma(t)^{-1}[\mu(t)-r(t)]
$$

exists and is bounded. As a result, the state-price density of the economy is given by

$$
H(t)=\exp \left(-\int_{0}^{t} r(s) d s-\frac{1}{2} \int_{0}^{t}\|\theta(s)\|^{2} d s-\int_{0}^{t} \theta^{\prime}(s) d B(s)\right)
$$

with $H(0)=H_{0}=1$. 
Preferences The loss averse investor is equipped with the following s-shaped utility of consumption

$$
U(c(t), Z(t))= \begin{cases}-B \frac{(Z(t)-c(t)))^{1-\gamma}}{1-\gamma}, & \text { if } c(t)<Z(t) \\ \frac{(c(t)-Z(t))^{1-\gamma}}{1-\gamma}, & \text { if } c(t) \geq Z(t)\end{cases}
$$

where $B$ is the parameter of loss aversion, $\gamma<1^{1}, c(t)$ is the consumption rate and $Z(t)$ is the reference level of consumption at time $t$. The investors has a constant subsistence level of consumption $\underline{Z}$ such that $0 \leq \underline{Z}<Z(t) \forall t$. The utility function 5 is steeper for losses than for gains, concave above the reference level of consumption and convex below it, as illustrated in Figure 1 below.

Insert Figure 1 about here

The reference level $Z(t)$ evolves over time as follows

$$
d Z(t)=(1-\alpha) \nu Z_{0} d t+\alpha d c(t)
$$

where $0 \leq \alpha<1$ and $\nu \leq 0$. $Z(t)$ can be expressed in the integral form

$$
Z(t)=Z_{0}+(1-\alpha) \nu Z_{0} t+\alpha[c(t)-c(0)]
$$

In other words, the investor's reference level evolves over time as a weighted average between the initial reference level and changes in consumption. $\alpha$ governs the degree of history dependence in the habit process: when $\alpha$ is large, the habit process depends heavily on current changes in consumption; Differently, if $\alpha$ is small the current habit level is more affected by past stock of habits ${ }^{2}$. In the limit when $\alpha=0$ the reference level

\footnotetext{
${ }^{1}$ There are two reasons for assuming $\gamma<1$. First, the empirical estimation of loss aversion parameters, starting from the seminal works of Kahneman and Tversky $(1979,1991,1992)$, strongly suggest $\gamma<$ 1. Second, for $\gamma \geq 1$ the utility in 5 would be discontinuous at $c=z$, thus, rendering the problem considerably more difficult. See also Berkelaar et al. (2004).

${ }^{2}$ Further economic interpretation of the reference level process can be found in Section 4.3 below.
} 
declines over time at the rate $\nu<0^{3}$. The initial value of habit, $Z_{0}$, is interpreted as inherited habits or, in other words, the reference level based on previous experiences.

The reference level of Eq 6 differs from the usual reference level process in the habit formation literature which typically assumes that the reference level is a linear combination of the initial reference and the entire history of past consumption (Sundaresan (1989), Constantinides (1990), Detemple and Zapatero (1991), Detemple and Zapatero (1992), Hindy et al. (1997), Bodie et al. (2008) and Munk (2008)). In contrast, in this paper I assume the reference level depend only on the initial and the last consumption level. There are several justification for this choice. First, psychology research suggests that individuals tend to remember better the first and the last elements of a sequence of items showed (a review of this literature is provided by Ashenazi et al. (2005)). Second, the financial literature have documented that investors are often prone to the availability bias (Barberis and Thaler (2003)), that is, they tend to assign more importance on recent information than past information. Third, Lynch and Randall (2011) show that a model where the most recent realizations of consumption contribute over $98 \%$ to the reference level of consumption is consistent with the micro evidence on habit formation (Ravina (2007)) and also explains several features of financial markets like the value premium, returns predictability and the serial correlation of the price-dividend ratio of aggregate equity.

Finally, there is also a technical reason for not using a reference level that depends on the entire history of past consumption. As will become clear in Section 3 below, the optimal consumption of the loss averse investor is discontinuous. When the state price density is above a given threshold, the optimal consumption descends to the subsistence level. When the state-price density is below the threshold, the optimal consumption jumps above the reference level. If the reference level depends on past consumption, the loss averse agent will have to take into account the effect of current consumption choices on the future reference level. As a result, the threshold of the state-price density will depend on the expected value of the entire future consumption path, thus, rendering the model

\footnotetext{
${ }^{3}$ This property of the reference level is consistent with the habit formation literature. See for instance, Detemple and Zapatero (1991, 1992).
} 
analytically intractable. For these reasons, the reference level process used in this paper seems a reasonable departure from the existing habit formation literature.

The investor is endowed with initial wealth $W_{0}$ and, at each time, allocates wealth between the risky assets and the risk-less bond and decides the consumption rate $c(t) \geq \underline{Z}$. Let $\pi(t)=\left[\pi_{1}(t), \pi_{2}(t), \ldots \pi_{d}(t)\right]^{\prime}$ be the fraction of wealth allocated to the risky assets. $c$ and $\pi$ are assumed to be $\mathcal{F}$-adapted and to satisfy the integrability condition $\int_{0}^{T}\left(c(t)+\|\pi(t)\|^{2} d t\right)<\infty$. A pair of consumption and portfolio process $(c, \pi)$ is admissible, given the initial wealth $W_{0}$, if satisfies the dynamic budget constraint

$$
d W(t)=W(t) r(t) d t+(\mu(t)-r(t) \imath)^{\prime} \pi(t) W(t) d t+\sigma^{\prime} \pi(t) W(t) d B(t)-c(t) d t .
$$

where $\imath$ denotes the $d \times 1$ unit vector. To ensure that the investor's problem is well defined I assume that the initial wealth is enough to finance the subsistence level of consumption, that is $W_{0} \geq \underline{Z} \mathbb{E}\left[\int_{0}^{T} \frac{H(t)}{H(0)} d t\right]$.

Under the conditions described above, the investor's maximization problem is defined as

$$
\max _{c(t)} \mathbb{E}\left[\int_{0}^{T} e^{-\rho t} U(c(t), Z(t)) d t\right]
$$

subject to the dynamic budget constraint 8 and the subsistence level constraint $c(t) \geq \underline{Z}$. Note that, given the s-shape of the utility function, 9 is a non-concave optimization problem. In Section 3 below I show how to solve this non-standard dynamic optimization problem and study the implications of loss aversion for the investor's consumption and portfolio choice. 


\section{Optimal consumption and portfolio rules}

In a complete market, the dynamic optimization problem 9 can be formulated as (see Cox and Huang (1989), Karatzas et al. (1987), Pliska (1986) for more details)

$$
\begin{aligned}
& \max _{c(t)} \mathbb{E}\left[\int_{0}^{T} e^{-\rho t} U(c(t), Z(t)) d t\right] \\
& \text { s.t. } \quad \mathbb{E}\left[\int_{0}^{T} H(t) c(t) d t\right] \leq H(0) W(0), \quad c(t) \geq \underline{Z} \quad \forall t .
\end{aligned}
$$

I solve the maximization problem 10 following Berkelaar et al. (2004). First, substituting the reference point 7 into the utility function 5 we obtain

$$
U(c(t), \hat{Z}(t))= \begin{cases}-B(1-\alpha)^{1-\gamma} \frac{(\hat{Z}(t)-c(t)))^{1-\gamma}}{1-\gamma}, & \text { if } c(t)<\hat{Z}(t), \\ (1-\alpha)^{1-\gamma} \frac{(c(t)-\hat{Z}(t))^{1-\gamma}}{1-\gamma}, & \text { if } c(t) \geq \hat{Z}(t),\end{cases}
$$

where

$$
\hat{Z}(t)=\frac{Z_{0}[1+(1-\alpha) \nu t]-\alpha c(0)}{1-\alpha}
$$

Therefore, the problem of a loss averse investor with stochastic reference level of consumption $Z(t)$ is equivalent to the problem of a loss averse investor with non-random (but still time-varying) reference level $\hat{Z}(t)^{4}$. The reference level $\hat{Z}(t)$ is endogenous because the initial consumption is part of the investor's maximization problem ${ }^{5}$.

The optimal consumption rate of the loss averse investor is derived in Proposition 1 below.

Proposition 1 The optimal consumption rate of the loss averse investor is given by

$$
c^{*}(H(t), \hat{Z}(t))= \begin{cases}\underline{Z}, & \text { if } x(t)>\bar{x}(t), \\ \hat{Z}(t)+x(t)^{-\frac{1}{\gamma}}, & \text { if } x(t) \leq \bar{x}(t)\end{cases}
$$

\footnotetext{
${ }^{4}$ Note that the constant $(1-\alpha)^{1-\gamma}$ is irrelevant for the maximization problem.

${ }^{5}$ More details about the initial consumption $c(0)$ are provided in Section 4.3.
} 
where $x(t) \equiv e^{\rho t} \lambda H(t), \bar{x}(t)$ is implicitly defined by

$$
\bar{x}(t)^{1-\frac{1}{\gamma}} \frac{\gamma}{1-\gamma}-\bar{x}(t)(\hat{Z}(t)-\underline{Z})+B \frac{(\hat{Z}(t)-\underline{Z})^{1-\gamma}}{1-\gamma}=0,
$$

$\lambda$ is the Lagrange multiplier associated to the static budget constraint and satisfies

$$
\mathbb{E} \int_{0}^{T}\left[H(s)\left(\hat{Z}(s)-\underline{Z}+x(s)^{-\frac{1}{\gamma}}\right) \mathbb{1}_{(x(s) \leq \bar{x}(t))}\right] d s+\underline{Z} \mathbb{E} \int_{0}^{T} H(s) d s=H(0) W(0) .
$$

Proposition 1 says that the optimal consumption rate of the loss averse investor is discontinuous: when the state-price density falls below the threshold $\bar{H}(t)=\frac{e^{-\rho t} \bar{x}(t)}{\lambda}$, the optimal consumption jumps above the reference level $\hat{Z}(t)$; when the state-price density exceeds the threshold $\bar{H}(t)$, the optimal consumption falls to the reference level $\underline{Z}$. ${ }^{6}$ When consumption is expensive (i.e. when $H(t)>\bar{H}(t)$ ), the loss averse investor refrains from consumption and invests as much wealth as possible in the market in order to maximize the probability that future consumption beats the reference level.

In other words, the loss averse investor tends to smooth consumption in good times to a greater extent than in bad times, thus giving rise to a pro cyclical consumption smoothing behaviour. This pro-cyclical behaviour of consumption smoothing is in line with the new empirical evidence provided by Hoffmann and Scherbakova-Stewen (2011).

In order to satisfy the budget constraint, the value of investor's wealth at any time $t$ must equal the present value of future consumption discounted by the state-price density.

\footnotetext{
${ }^{6}$ In the limit as $\underline{Z} \longrightarrow 0$ the optimal consumption falls to zero in bad times. Zero consumption may appears to be counter-intuitive at a first glance. However, $c(t)$ does not have to be the investor's total consumption. For instance, one can think about $w(t)$ as the wealth the investor keeps in some trading account and $c(t)$ can be interpreted as the amount of money withdrawn from the trading account at each point in time. In addition to the money invested in the trading account, the investor may receive labour income to finance his/her desired consumption. Naturally, a rational investor would take into account the relation between labour income and financial wealth when choosing the optimal portfolio. However, if the loss averse investor is prone to narrow framing (Barberis et al. (2006)), he/she will tend to make financial decisions in isolation, regardless of other sources of risk. This interpretation should make less puzzling the limiting case of zero consumption.
} 
More formally,

$$
\begin{aligned}
W(t) & =\mathbb{E}\left[\int_{0}^{T} \frac{H(s)}{H(t)} c^{*}(H(s), \hat{Z}(s))\right] d s \\
& =\mathbb{E}_{t} \int_{t}^{T}\left[(\hat{Z}(s)-\underline{Z}) \frac{H(s)}{H(t)} \mathbb{1}_{(H(s) \leq H(s))}\right] d s+\ldots \\
& \ldots+e^{-\frac{\rho t}{\gamma}} H(t)^{-\frac{1}{\gamma}} \mathbb{E}_{t} \int_{t}^{T} e^{-\frac{\rho(s-t)}{\gamma}}\left[\left(\frac{H(s)}{H(t)}\right)^{1-1 / \gamma} \mathbb{1}_{(H(s) \leq H(s))}\right] d s+\underline{Z} \mathbb{E}_{t} \int_{t}^{T} \frac{H(s)}{H(t)} d s
\end{aligned}
$$

The investor's wealth is like a portfolio of binary options (the first and second term on the right hand side of 16) and zero-coupon bonds (the third term on the right hand side of 16). The binary options deliver consumption in excess of the subsistence level only if the price of the consumption good (i.e. the state-price density) is below the threshold $\bar{H}(t)$. The zero-coupon bonds pay the subsistence level $\underline{Z}$ at any point in time. This differs from the case of smooth power utility of consumption where the investor's wealth comprises only a portfolio of bonds that pay consumption as a coupon, independently of consumption price (see Wachter (2002) for more details).

If we further assume that the risk-free rate and the Sharpe ratio are constant (i.e. constant investment opportunity set), the optimal wealth takes the following form:

Proposition 2 The optimal wealth of the loss averse investor, along the optimal consumption strategy is given by

$$
\begin{aligned}
W(t, H)= & \int_{t}^{T} \hat{Z}(s) e^{-r(s-t)} N\left(d_{1}(s)\right) d s+\lambda^{-\frac{1}{\gamma}} e^{-\frac{\rho t}{\gamma}} H(t)^{-\frac{1}{\gamma}} \int_{t}^{T} e^{-\Gamma(s-t)} N\left(d_{2}(s)\right) d s \\
& +\underline{Z} \int_{t}^{T} e^{-r(s-t)}\left(1-N\left(d_{1}(s)\right)\right) d s
\end{aligned}
$$


where $N(x)$ is the cumulative standard normal distribution function evaluated at $x$ and

$$
\begin{aligned}
& d_{1}=\frac{\log \left(\frac{\bar{H}(s)}{H(t)}\right)+r(s-t)-\frac{1}{2}\|\theta\|^{2}(s-t)}{\|\theta\| \sqrt{s-t}} \\
& d_{2}=d_{1}+\frac{\|\theta\| \sqrt{s-t}}{\gamma} \\
& \Gamma=\frac{\rho}{\gamma}+(1-1 / \gamma)\left(r+\frac{\|\theta\|^{2}}{2 \gamma}\right)
\end{aligned}
$$

Financial wealth is monotonically decreasing in the state price density and goes to zero (infinity) as the state price density goes to infinity (zero). Therefore, the loss averse investor is able to sustain consumption above the reference level as long as his/her total wealth exceeds the threshold $W(t, \bar{H}(t))$ and descends to the subsistence level otherwise. This result is consistent with Foellmi et al. (2011) who show that rich agents smooth consumption to a larger extent than poor agents. Finally, it is worth emphasizing that the assumption of constant investment opportunity set is made only for simplicity. The financial wealth of the loss averse investor can be computed analytically for any investment opportunity set in the affine jump-diffusion class by using the transform analysis of Duffie et al. (2000).

The optimal portfolio of the loss averse agent can be obtained by applying Ito's lemma on Eq. (17) and comparing the coefficients with the dynamic budget constraint (8). The solution will be characterized in terms of the functions $F(t)$, defined as the presented value of the reference level and the subsistence level discounted at the state price density

$$
F(t)=\int_{t}^{T} \hat{Z}(s) e^{-r(s-t)} N\left(d_{1}(s)\right) d s+\int_{t}^{T} \underline{Z}(s) e^{-r(s-t)}\left(1-N\left(d_{1}(s)\right)\right) d s
$$

and $G(t)$, the desired excess consumption in good times (i.e., when $H(t) \leq \bar{H}(t)$ ), that is

$$
G(t)=\lambda^{-\frac{1}{\gamma}} e^{-\frac{\rho t}{\gamma}} H(t)^{-\frac{1}{\gamma}}
$$


Proposition 3 The optimal stock allocation of the loss averse investor is given by

$$
\pi(t)=\pi_{1}(t)+\pi_{2}(t)+\pi_{3}(t)
$$

where:

$$
\begin{aligned}
& \pi_{1}(t)=\left(\sigma^{\prime}\right)^{-1} \frac{\theta}{\gamma} \frac{W(t, H(t))-F(t)}{W(t, H(t))} \\
& \pi_{2}(t)=\left(\sigma^{\prime}\right)^{-1} \frac{G(t)}{W(t, H(t))} \int_{t}^{T} e^{-\Gamma(s-t)} \frac{\phi\left(d_{2}(s)\right)}{\|\theta\| \sqrt{s-t}} d s \\
& \pi_{3}(t)=\frac{\left(\sigma^{\prime}\right)^{-1} \theta}{W(t, H(t))} \int_{t}^{T} e^{-r(s-t)}(\hat{Z}(s)-\underline{Z}) \frac{\phi\left(d_{1}(s)\right)}{\|\theta\| \sqrt{s-t}} d s
\end{aligned}
$$

and $\phi(x)$ is the standard normal density function evaluated at $x$.

Proposition 3 says that the optimal portfolio of the loss averse investor has three components. The first component, $\pi_{1}$, represents the investment in the mean-variance portfolio. As in the classic portfolio theory, the specific position in the mean-variance portfolio is determined by the investor's relative risk tolerance of wealth (i.e., $\left.\frac{W(t, H)-F(t)}{\gamma W(t, H)}\right)$ computed from the concave part of the indirect utility. Note that, because the investor's risk tolerance decreases in bad times, the investment in the mean-variance portfolio decreases when consumption price increases ${ }^{7}$. The other two components, $\pi_{2}$ and $\pi_{3}$ are gambling portfolios originating from the risk seeking behaviour over losses. To see why, note that if consumption is always above the reference level, then $N(x)=1$ and $\phi(x)=0$ at any point in time, which implies that $\pi_{2}=\pi_{3}=0$. The portfolio $\pi_{2}$ reflects the desire of loss averse investors to consume less and invest more in risky assets when consumption becomes expensive: in good times, the fraction of wealth $G(t) / W(t, H(t))$ is allocated to consumption, while, when consumption is expensive, the investor decreases consumption to the subsistence level and the fraction of wealth $G(t) / W(t, H(t))$ is now being invested in the risky asset. The portfolio $\pi_{3}$ represents the investment in stocks which is necessary to finance an increase in consumption to the reference level when consumption becomes

\footnotetext{
${ }^{7}$ More technically, using the fact that $H(t)^{-1 / \gamma}$ and $N(x)$ are both decreasing in $H(t)$, it is easy to verify that $\frac{W(t, H)-F(t)}{\gamma W(t, H)}$ is decreasing in $H(t)$.
} 
cheaper. It is important to note that $\phi(x)$ depends positively on the state price density and, thus, the relative importance of gambling portfolios increases in bad times when consumption is expensive. In summary, the optimal portfolio of the loss averse investor can be expressed as a combination of a mean-variance portfolio $\left(\pi_{1}\right)$ and a gambling portfolio $\left(\pi_{2}+\pi_{3}\right)$, where the relative importance of the mean-variance portfolio (gambling portfolio) increases in good times (bad times).

The quantitative implications of these portfolio strategies are analysed in Section 4 below.

\section{Discussion}

In this section I study the implications of loss aversion and time variation in the reference level for consumption and portfolio rules. In order to easy the interpretation of results, I assume that there is only one risky asset (the stock) and one risk-free asset (the bond). For comparison, I also analyse optimal consumption and portfolio rules of a consumption insurer (i.e. an investor whose consumption is not allowed to descend below the reference level) and those of an investor with power utility of consumption (i.e. a CRRA investor). The consumption-investment choice of these two investors is reported in Appendix 6.0.2.

\subsection{Consumption and portfolio rules}

Figure 2 shows consumption and portfolio choices of the three investors considered. To establish a benchmark case, and to emphasize the effect of loss aversion, I set $\alpha=\nu=0$ so that the reference level of consumption is constant at the level $Z_{0}$. The remaining parameters, reported in Table 1 , are standard in the literature of loss aversion. $B=2.2 .5$ and $\gamma=.2$ reflect the empirical/experimental evidence on loss aversion ( Kahneman and Tversky (1979, 1991, 1992), Berkelaar et al. (2004)). The initial reference level $Z_{0}=2$ is chosen for illustrative purposes only. Larger reference level would only increase the risk seeking region without affecting the state-dependent dynamics of consumption 
and portfolios. By inspection of Proposition 3 we see that the the subsistence level of consumption affects the portfolio of the loss averse investor only through the difference $\hat{Z}-\underline{Z}$. Therefore, I set $\underline{Z}=0$ without loss of generality.

Insert Figure 2 about here

We observe that the consumption insurer has a smaller fraction of wealth invested in stock than the investor with smooth power utility. This is due to the fact that bonds are better investment opportunities to ensure that consumption does not fall below a given reference level. In other words, the necessity to establish a lower bound on consumption implies a lower investment in stocks. This result also obtains in models with more complicate dynamics of the reference level of consumption (see, for instance, Munk (2008) where the reference level is a geometric average of past consumption). Moreover, the fraction of wealth invested in stocks by the consumption insurer is monotonically decreasing in the state-price density: when consumption price increases, it becomes more difficult to ensure that future consumption does not fall below the reference level and the bond allocation needs to increase.

The loss averse investor follows a strategy which appears intermediate between the other two: for low values of the state-price density, the portfolio strategy of the loss averse investor is similar to that of the consumption insurer; instead, for large values of the state-price density, the loss averse investor becomes risk seeking, the fraction of wealth invested in the stock increases and exceeds that of the investor with power utility. Interestingly, the subsistence strategy is abandoned when the state-price density is still below $\bar{H}(t)$. This suggests that the loss averse investor anticipates future increases in the consumption price over the threshold $\bar{H}(t)$ and modifies portfolio investments today.

The right upper-panel of Figure 2 shows the consumption-wealth ratio as a function of the state-price density. While the CRRA investor and the consumption insurer smooth consumption over different states of the world, the loss averse investor concentrates consumption expenditures in good states (i.e. when consumption is cheap), and increases 
investment in the risky assets in bad times (i.e. when consumption is expensive). For example, the investor with power utility consumes about $1 \%$ of his/her wealth, independently of economic conditions. The fraction of wealth consumed by the consumption insurer increases with the state price density and converges to about $25 \%$. The fraction of wealth consumed by the loss averse investor is much higher, increases up to $50 \%$ and then drops to zero for large values of the state-price density. The lower panels of Figure 2 analyse consumption-portfolio choices as a function of the investor's wealth. Given that wealth is a monotonic decreasing function of the state-price density, the figures appear as the mirror image of figures in the upper panels and can be interpreted accordingly.

Figure 3 reports the mean-variance and the gambling portfolios as a function of the state-price density. We observe that the gambling portfolio approaches zero in very good time and increases until the state-price density reaches the threshold $\bar{H}(t)$. After the threshold, the gambling portfolio is still increasing but at a lower rate. The mean variance portfolio has a different dynamics. It is very large in good times and declines fast as the state-price density approaches the threshold $\bar{H}(t)$. After that, it converges to a constant small value. Overall, mean-variance and gambling portfolios have a specular dynamics except for very low and very large values of the state price density: the loss averse investor completely abandons the gambling portfolio in good times but keeps some fraction of wealth invested in the mean-variance portfolio even in very bad times.

Insert Figure 3 about here

In summary, the optimal strategy of the loss averse investor can be understood as follow: in good times, the investor adopts a consumption insurer strategy in order to minimize the fluctuations of consumption around the reference level; in bad times the investor decreases consumption and opts for a gamble-for-resurrection strategy that, instead, increases the probability that future consumption exceeds the reference level of consumption. 


\subsection{Time diversification}

A typical recommendation of professional advisers is that the investment in stocks should increase with the investment' horizon. The consistency of this advice with results of portfolio theory was addressed by many researchers. Kim and Omberg (1996) show that for investors with utility over terminal wealth, the optimal stock allocation increases with the investment horizon when the coefficient of risk aversion is bigger than one and the risk premium is positive. A similar result is obtained by Wachter (2002) for the case of power utility of consumption.

In Figure 4 I plot the proportion of wealth invested in stocks by the loss averse investors and, for comparison, the optimal proportions of the consumption insurer and that of the CRRA investor. Ensuring the reference level of consumption over a longer period is costly and generates additional precautionary saving behaviour. Therefore the optimal allocation of the consumption insurer decreases with the investment horizon. For the loss averse investor the relation between investment and horizon is more delicate: on the one hand, an increase in the horizon generates additional precautionary saving behaviour, thus, decreasing the allocation to stocks; on the other hand, for longer horizon, ensuring a given level of consumption may become too costly, and the precautionary saving behaviour is gradually abandoned. Figure 4 confirms this intuition: the fraction of wealth invested in the stock by the loss averse investor decreases with $T$ initially, (for $T$ less than 5 years) and then starts increasing. We conclude that the optimal strategy of loss averse investor agrees with the recommendation of professional advisers, only for sufficiently large trading horizons.

Insert Figure 4 about here

\subsection{The effect of history dependence in the reference level}

The habit formation literature has analysed the effect of the reference level of consumption on portfolio choices (Detemple and Zapatero (1992), Hindy et al. (1997), Bodie 
et al. (2008), Munk (2008)) and on equilibrium asset prices (Sundaresan (1989), Constantinides (1990), Detemple and Zapatero (1991) and Campbell and Cochrane (1999)). This literature typically assumes that consumption never falls below the habit level (i.e. the addictive property of habit). This property seems counter-intuitive especially during economic downturns. In contrast, the s-shaped utility allows consumption to fall below the reference level in bad times, thus making it possible to provide a more general characterization of the effect of the reference level on optimal consumption-investment strategies.

Figure 5 shows that the effect of history dependence in the reference level on the portfolio of the loss averse investor depends on the economic conditions: in good time (i.e. for low values of the state-price density), an increase in $\alpha$, increases the fraction of wealth invested in bonds; on the contrary, in bad times the fraction of wealth invested in stocks decreases with $\alpha$. In order to understand this result we need to answer the following question: how does the degree of history dependence in the reference level affect the current reference level of consumption? By differentiating $\hat{Z}(t)$ with respect to $\alpha$ we obtain

$$
\frac{\partial \hat{Z}(t)}{\partial \alpha}=\frac{Z(0)-c(0)-\alpha \frac{\partial c(0)}{\partial \alpha}}{(1-\alpha)^{2}} \quad \forall t
$$

The first panel of Figure 5 shows the optimal initial consumption ${ }^{8}$ and the corresponding reference level as a function of $\alpha$. Given the choice of parameters, the investor chooses optimally $c(0)>\hat{Z}(0)$. When consumption exceeds the reference level, the investor is riskaverse and dislikes variation in the excess consumption (i.e., variations in $c(0)-\hat{Z}(0)$ ). This is evident from Figure 5 where we observe that the difference $c(0)-\hat{Z}(0)$ does not change with $\alpha$. Note that $\frac{\partial \hat{Z}(t)}{\partial \alpha}$ does not depend on time. Therefore, we conclude that an increase in $\alpha$ reduces the reference level at any point in time. As a result, when $\alpha$ increases, the loss averse investor modifies his/her portfolio in order to finance a now smaller reference level of consumption. The smaller reference level reduces the necessity to invest in bonds in

\footnotetext{
${ }^{8}$ The consumption at time $t=0$ is computed from Proposition 1 by solving jointly the equations 13 , 14 and 15 for the triple $(c(0), \bar{x}, \lambda)$ when the initial value of the state-price density is $H_{0}=1$.
} 
good times (and therefore increases the optimal fraction of wealth invested in stocks) and decreases risk-taking incentives in bad times (and therefore decreases the optimal fraction of wealth invested in stocks). Naturally, the opposite behaviour would be observed if $C(0)-\hat{Z}(0)<0$.

Insert Figure 5 about here

These results can be summarized in the following way: time variation in the reference level introduces a link between past (initial) consumption and the current portfolio choice that depends on whether the investor has experienced previous gains or losses in consumption. If initial consumption exceeds the reference level, an increase in the importance past consumption makes the investor less risk-averse in good times, less risk seeking in bad times and the fraction of wealth invested in stocks changes accordingly. Differently, if the investor has experienced previous losses in consumption, an increase in the importance of past consumption makes him/her more risk-averse in good times and more risk seeking in bad times, thus, decreasing (increasing) the fraction of wealth invested in stocks in good (bad) times.

In this framework, consumption gain/losses can be used to rationalize several stylized facts of the investors' trading behaviour. In a recent paper Dorn and Weber (2013) show that many investors increased their allocation to stocks during the recent financial crisis. Guvenen (2011) finds that investors with many financial assets smooth consumption to a lesser extent than investors with few financial assets. These findings are consistent with the behaviour of loss averse investors who react to consumption losses by rebalancing their portfolio toward stocks (and reduce consumption smoothing behaviour) in order to increase the probability of beating their reference level of consumption in the future.

\subsection{Performance of optimal portfolios}

In this section I discuss the implications of loss aversion for the risk-return trade off of the investor's wealth. The idea behind this analysis is that the risk-return trade off 
of financial wealth provides an additional interpretation of the consumption-investment strategy of the loss averse investor. In particular, I study expected returns and Sharpe ratios of the investor's wealth. For comparison, I also analyse returns and Sharpe ratio of the consumption insurer and those of an investor with power utility of consumption. A comprehensive analysis of the portfolio performance for the different cases of loss aversion over financial wealth is provided by Fortina and Hlouskovaa (2011) and Zakamouline $(2014)$.

The main intuition for the results of this Section relies on the previously described effect of the reference level of consumption on portfolio rules. Financing a larger reference level of consumption, or the same reference level for longer horizons, requires a larger investment in the bond. This depresses the performance of portfolios because, on average, stocks return more than bonds.

Figure 6 shows these results in more detail. Expected returns and Sharpe ratio of the consumption insurer decreases with the reference level ${ }^{9}$. For the loss averse investor this relation is non-monotone: in good times the reference level of consumption depresses the performance of portfolios; in bad times, higher reference levels of consumption imply more risk seeking behaviour and, in turn, larger investments in stocks. As a result, portfolio performances increase and exceed those of the CRRA investor. This means that the gambling-for-resurrection strategy of the loss averse investor actually does what is supposed to do: it increases the expected return on wealth, as compared to other strategies, and enhances the probability that future consumption beats the reference level.

The second row of Figure 6 shows the effect of the investor's level of loss aversion $B$. An increase in $B$, implies an increase in the threshold of consumption prices $\bar{x}^{10}$. Thus, the loss averse investor is willing to sustain the reference level of consumption even for higher consumption prices. This increases the fraction of wealth invested in bonds and depresses the performance of portfolio.

\footnotetext{
${ }^{9}$ Note that, for large values of the state-price density the consumption insurer invests $100 \%$ of wealth in the bond. As a result, the volatility of wealth goes to zero and the Sharpe ratio is not defined. To create Figure, 6 I truncate the Sharpe ratio of the consumption insurer at -1 .

${ }^{10} \mathrm{~A}$ formal proof of this statement can be found in Berkelaar et al. (2004) for case of utility of final wealth. The proof for the case of inter-temporal consumption is similar, thus, not reported for brevity.
} 
Figure 6 also shows the effect of the investment horizon for $T=[4,7,10]$. Consistently with the discussion in Section 4.2, we see that the horizon increases the risk-taking taking incentives and improves the performance of portfolios in good times. In bad times, we observe the opposite result: expected returns of short-horizon loss averse investors are larger that that of long horizons investors. This suggests that, in bad times, risk-taking incentives decrease with the remaining horizon. In other words, once the loss averse investor opts for the gambling-for-resurrection strategy, the aggressiveness of the strategy depends on the remaining horizon. If the horizon is very short the loss averse investor has, in a sense, nothing to loose because he/she will suffer the potential negative effects of the risky strategy only for a short time period. As a result, the investor is willing to take on more risk. Differently, for longer horizon the risk-taking strategy is less aggressive because the investor take into account that the negative effects may last for longer time.

The effect of history dependence in the habit process on portfolio performance can be deduced from the results of the Section 4.3. If the investor has experienced previous gains in consumption, the fraction of wealth invested in stocks increases (decreases) with $\alpha$ in good (bad) times. Consistently, increasing the weight of current consumption in the dynamic updating of the reference point improves (decreases) portfolio performance in good (bad) times.

These results confirm the analysis developed in the previous sections and make less puzzling the recent evidence on investors' trading behaviour. Why are some investors willing to increase their exposure to equity during the financial crisis? The analysis developed in this paragraph provides a simple answer: investors who experienced previous consumption losses and/or those with a short investment horizon decide to invest more in stocks in bad times in order to increase the Sharpe ratio of their total wealth. In addition, among the investors who experienced previous consumption losses, those who give more importance to recent consumption (i.e., those with high $\alpha$ ) are more motivated to make up consumption losses and, as a result, trade more aggressively in stocks. These results 
call for further empirical studies.

\section{Conclusion}

Despite the economic and empirical relevance of loss aversion, very little is known about the consumption and portfolio rules of investors with s-shaped utility of consumption. In this paper, the consumption investment problem of a loss averse investor with time varying reference level of consumption is characterized and solved analytically. The optimal portfolio of the loss averse investor consists of two components: a mean variance component and a gambling component aggressively invested in stocks. Moreover, the importance of these two components is time-varying: the optimal portfolio is biased toward the mean-variance component in good times and toward the gambling component in bad times. The consumption-investment behaviour of the loss averse investor is consistent with the recent empirical evidence on investors' consumption-smoothing and trading behaviour, especially during financial crises.

To keep the problem as simple as possible and to highlight the link between loss aversion and the consumption-portfolio policy, I study the case of constant investment opportunity set only. Even if this simple model is consistent with several styled facts on investors' behaviour, it would be interesting to analyse the portfolio problem in a more general financial market, for instance with stochastic interest rates and/or mean reversion in stock returns. The main challenge, in this framework, would be to price binary options under more general affine-diffusion processes for the underlying state variables. This pricing problem can be solved with the help of the transform analysis of Duffie et al. (2000). This idea is left for future research. 


\section{References}

Ashenazi, A., E. J. Davelaar, Z. Goshen-Gottsein, H. J. Haarmann, and M. Usher. 2005. The demise of short term memory revised: empirical and computational invbestigations of recency effects. Psychological Review 112:3-42.

Barberis, N., M. Huang, and T. Santos. 2001. Prospect theory and asset prices. Quarterly Journal of Economics 116:1-53.

Barberis, N., M. Huang, and R. H. Thaler. 2006. Individual preferences, monetary gambles and stock market participation: a case of narrow framing. The American Economic Review 96:1069-1090.

Barberis, N., and R. Thaler. 2003. A survey of behavioral finance. Handbook of the Economics of Finance 1:1053-1128.

Benartzi, S., and R. H. Thaler. 1995. Myopic loss aversion and the equity premium puzzle. Quarterly Journal of Economics 110:73-92.

Berkelaar, A. B., R. Kouwenberg, and T. Post. 2004. Optimal portfolio choice under loss aversion. The Review of Economics and Statistics 86:973-987.

Bodie, Z., J. B. Detemple, S. Otruba, and S. Walter. 2008. Optimal consumption-portfolio choices and retirement planning. Journal of Economic Dynamics and Control 28:11151148.

Brennen, M., E. S. Schwartz, and R. Lagnado. 1997. Strategic asset allocation. Journal of Economic Dynamics and Control 21:1377-1403.

Campbell, J., and J. Cochrane. 1999. By force of habit: a consumption based explanation of aggregate stock market behavior. Journal of Political Economy 107:205-251.

Constantinides, G. 1990. Habit formation: a resolution of the equity premium puzzle. Journal of Political Economy 98:519-543. 
Cox, J. C., and C. F. Huang. 1989. Optimal consumption and portfolio policies when asset prices follow a diffusion process. Journal of Economic Theory 49:33-83.

Curatola, G. 2015. Loss aversion habit formation and the term structures of equity and interest rates. Journal of Economic Dynamics and Control 53:103-122.

Detemple, J. B., and F. Zapatero. 1991. Asset prices in an exchange economy with habit formation. Econometrica 59:1633-1657.

Detemple, J. B., and F. Zapatero. 1992. Optimal consumption-portfolio policies with habit formation. Methematical Finance 2:35-58.

Dimmock, S. G., and R. Kouwenberg. 2010. Loss-aversion and household portfolio choices. Journal of Empirical Finance 17:441-459.

Dorn, D., and M. Weber. 2013. Individual investors' trading in times of crisis: going it alone or giving up? Working Paper .

Duffie, D., J. Pan, and K. Singleton. 2000. Transform analysis and asset pricing for affine jump-diffusions. Econometrica 68:1343-1376.

Foellmi, R., R. Rosenblatt-Wisch, and K. R. Schenk-Hoppé. 2011. Consumption path under prospect untility in an optimal growth model. Journal of Economic Dynamics and Control 35:273-281.

Fortina, I., and J. Hlouskovaa. 2011. Optimal asset allocation under linear loss aversion. Journal of Banking and Finance 35:2974-2990.

Frühwirth, M., and G. Mikula. 2008. Can prospect theory explain the popularity of saving plans?

Gomes, F. J. 2005. Portfolio choice and trading volume with loss-averse investors. Journal of Business 78:675-706.

Guvenen, F. 2011. Do stockholders share risk more efficiently than non stockholders? Review of Economics and Statistics 89:275-288. 
Hens, T., and M. Vlcek. 2011. Can prospect theory explain the disposition effect? Journal of behavioral finance 12:141-157.

Hindy, A., C. Huang, and S. H. Zhu. 1997. Optimal consumption and portfolio rules with durability and habit formation. Journal of Economic Dynamics and Control 21:525550.

Hoffmann, M., and I. Scherbakova-Stewen. 2011. Consumption risk sharing over the business cycle: the role of small firms' access to credit markets. The Review of Economics and Statistics 93:1403-1416.

Jin, H., and X. Zhou. 2008. Behavioral portfolio selection in continuous time. Mathematical Finance 18:385-426.

Kahneman, D., and A. Tversky. 1979. Prospect Theory: an analysis of decision under risk. Econometrica 47:263-290.

Kahneman, D., and A. Tversky. 1991. Loss aversion in riskless choice: a referencedependent model. The Quarterly Journal of Economics 5:297-323.

Kahneman, D., and A. Tversky. 1992. Advances in prospect theory: cumulative representation of uncertainty. Journal of Risk and Uncertainty 106:1039-1061.

Karatzas, I., J. Lehoczky, and S. Shreve. 1987. Optimal portfolio and consumption decisions for a small investors on a finite horizon. Siam Journal on Control and Optimization $25: 1157-1186$.

Kim, T. S., and E. Omberg. 1996. Dynamic non-myopic portfolio behavior. Review of financial Studies 9:141-161.

Lettau, M., and J. Wachter. 2007. Why is long-horizon equity less risky? a duration-based explantion of the value premium. Journal of Finance 62:55-92.

Lynch, A. W., and O. Randall. 2011. Why surplus consumption in the habit model may be less persistent than you think. Working Paper. 
Merton, R. 1969. Lifetime portfolio selection under uncertainty: the continuous-time case. Review of Economics and Statistics 52:247-257.

Merton, R. 1971. Optimum consumption and portfolio rules in a continuous-time model. Journal of Economic Theory 3:373-413.

Munk, C. 2008. Portfolio and consumption choice with stochastic investment opportunities and habit formation in preferences. Journal of Economic Dynamics and Control $32: 3560-3589$.

Odean, T. 1998. Are investors reluctant to realize their losses? Journal of Finance $53: 1775-1798$.

Pliska, S. 1986. A stochastic calculus model of continuous time trading: optimal portfolios. Mathematics of Operations Research 11:371-382.

Ravina, E. 2007. Habit persistence and keeping up with the Joneses: evidence from micro data. Working Paper .

Reichlin, C. 2013. Utility maximization with a given pricing measure when the utility is not necessarily concave. Mathematics and Financial Economics 7:531-556.

Sundaresan, S. 1989. Intertemporal dependent preferences and the volatility of consumption and wealth. Review of Financial Studies 2:73-89.

Wachter, J. 2002. Portfolio and consumption decisions under mean-rverting returns: an exact solution for complete markets. Journal of Financial and Quantitative Analysis $37: 63-91$.

Yogo, M. 2008. Asset prices under habit formation and reference-dependent preferences. Journal of Business and Economic Statistics 26:131-143.

Zakamouline, V. 2014. Portfolio performance evaluation with loss aversion. Quantitative Finance 14:699-710. 


\section{Appendix A: Mathematical proof}

\subsubsection{Consumption and portfolio rules of the loss averse investor}

I follow the methodology in Berkelaar et al. (2004). The time index is removed for simplicity. The power s-shaped utility is not quasi concave, thus, the first order conditions only describe local maxima: if $c<Z$ the utility function is convex and the Weirestrass theorem implies that the maximum must lie on the boundaries, $\underline{Z}$ or $Z$; If $c \geq Z$ the utility function is concave and the optimal consumption can be obtained by applying the Kuhn-Tucker theorem:

$$
\begin{gathered}
e^{-\rho t}(c-Z)^{-\gamma}=\lambda H-y \\
y(c-\underline{Z})=0, \quad \lambda, y \geq 0
\end{gathered}
$$

where $\lambda$ is the Lagrange multiplier associated to the budget constraint and $y$ the multiplier associated to the subsistence level constraint. The system 20 yields the following 3 local

maxima, $c_{1}=x^{-\frac{1}{\gamma}}+Z, c_{2}=Z$ and $c_{3}=\underline{Z}$, where $x=\lambda e^{\rho t} H$. Let the function $L: \mathbb{R} \rightarrow \mathbb{R}$ be the Legendre-Fenchel transform (or convex conjugate) of the investor's maximization problem:

$$
L(H, c)=\max _{c \geq 0}\left\{e^{-\rho t} U(c, z)-\lambda H c\right\}
$$

where $U(c, z)$ is defined in 1 . First, note that

$$
\begin{aligned}
& L\left(H, c_{1}\right)>L\left(H, c_{2}\right) \Longleftrightarrow \\
& x^{1-\frac{1}{\gamma}} \frac{\gamma}{1-\gamma} \geq 0 \Longleftrightarrow \\
& \gamma<1 .
\end{aligned}
$$


Thus, given the assumption $\gamma<1, c_{1}$ is always preferred to $c_{2}$. Second,

$$
\begin{aligned}
& L\left(H, c_{2}\right)>L\left(H, c_{3}\right) \Longleftrightarrow \\
& -x Z \geq-B \frac{(Z-\underline{Z})^{1-\gamma}}{1-\gamma}-x \underline{Z} \Longleftrightarrow \\
& x<x^{*} \equiv B \frac{(Z-\underline{Z})^{-\gamma}}{1-\gamma}
\end{aligned}
$$

The above inequality implies that, for $x<x^{*}, c_{1}$ is the optimal solution to the agent's maximization problem. Instead, when $x \geq x^{*}$ the optimal consumption is either $c_{1}$ or $c_{3}$ :

$$
\begin{aligned}
& L\left(H, c_{1}\right)>L\left(H, c_{3}\right) \Longleftrightarrow \\
& x^{1-\frac{1}{\gamma}} \frac{\gamma}{1-\gamma}-x Z \geq-B \frac{(Z-\underline{Z})^{1-\gamma}}{1-\gamma}-x \underline{Z} \Longleftrightarrow \\
& x^{1-\frac{1}{\gamma}} \frac{\gamma}{1-\gamma}-x(Z-\underline{Z})+B \frac{(Z-\underline{Z})^{1-\gamma}}{1-\gamma} \geq 0
\end{aligned}
$$

which leads to Eq. 14 in Proposition 1. Let $c^{*}$ be the consumption that maximizes $L(H, c)$ and $\tilde{c}$ any other solution to the investor's problem, satisfying the resource constraint either with equality or inequality. Thus

$$
\begin{aligned}
& \mathbb{E} \int_{0}^{\infty} e^{-\rho t} U\left(c^{*}, Z\right) d t-\mathbb{E} \int_{0}^{\infty} e^{-\rho t} U(\tilde{c}, Z) d t \\
& =\mathbb{E} \int_{0}^{\infty} e^{-\rho t} U\left(c^{*}, Z\right) d t-\mathbb{E} \int_{0}^{\infty} e^{-\rho t} U(\tilde{c}, Z) d t+\lambda w_{0}-\lambda w_{0} \\
& \geq \mathbb{E} \int_{0}^{\infty} e^{-\rho t}\left(U\left(c^{*}, Z\right)-U(\tilde{c}, Z)\right) d t+\lambda \int_{0}^{\infty} H c^{*} d s-\lambda \int_{0}^{\infty} H \tilde{c} d s \\
& =\mathbb{E} \int_{0}^{\infty} e^{-\rho t}\left[\left(U\left(c^{*}, Z\right)-x c^{*}\right)-(U(\tilde{c}, Z)-x \tilde{c})\right] d t \geq 0
\end{aligned}
$$

where, the first inequality follows because the resource constraint holds with equality for $c^{*}$ and with inequality for $\tilde{c}$; the last inequality follows because $c^{*}$ maximizes $L(H, c)$. This shows that $c^{*}$ solves the investor's problem. Let now

$$
f(x, Z) \equiv x^{1-\frac{1}{\gamma}} \frac{\gamma}{1-\gamma}-x(Z-\underline{Z})+B \frac{(Z-\underline{Z})^{1-\gamma}}{1-\gamma} .
$$


Thus,

$$
\begin{aligned}
& f\left(x^{*}, Z\right)=\left(x^{*}\right)^{1-\frac{1}{\gamma}} \frac{\gamma}{1-\gamma}>0, \\
& \lim _{x \rightarrow \infty} f(x, Z)=-\infty, \\
& \frac{\partial f}{\partial x}=-x^{-\frac{1}{\gamma}-1}-(Z-\underline{Z})<0
\end{aligned}
$$

which implies that Eq. $f(x, Z)=0$ admits a unique solution $\bar{x}$ in the interval $\left(x^{*}, \infty\right)$. We conclude that $c_{1}$ is optimal for any $x \leq \bar{x}$, and $c_{3}$ is optimal for any $x>\bar{x}$.

Given the optimal consumption $c^{*}$, the optimal financial wealth of the loss averse investor is given by

$$
\begin{aligned}
& W(t)=\mathbb{E}_{t} \int_{t}^{T}\left[\hat{Z}(s) \frac{H(s)}{H(t)} \mathbb{1}_{(H(s) \leq \bar{H})}\right] d s \\
& +e^{-\frac{\rho t}{\gamma}} H(t)^{-\frac{1}{\gamma}} \mathbb{E}_{t} \int_{t}^{T} e^{-\frac{\rho(s-t)}{\gamma}}\left[\left(\frac{H(s)}{H(t)}\right)^{1-1 / \gamma} \mathbb{1}_{(H(s) \leq \bar{H})}\right] d s+\underline{Z} \mathbb{E}_{t} \int_{t}^{T} \frac{H(s)}{H(t)} \mathbb{1}_{(H(s)>\bar{H})} d s
\end{aligned}
$$

Under the assumption of constant investment opportunity set, $H(s) / H(t)$ is a $\log$ normal random variable with mean $-\left(r+\frac{1}{2}\|\theta\|^{2}\right)(s-t)$ and variance $\|\theta\|^{2}(s-t)$. As a result,

$$
\begin{aligned}
& \mathbb{E}_{t}\left[\frac{H(s)}{H(t)} \mathbb{1}_{(H(s) \leq \bar{H})}\right]=e^{-r(s-t)} N\left(d_{1}\right) \\
& \mathbb{E}_{t}\left[\left(\frac{H(s)}{H(t)}\right)^{1-1 / \gamma} \mathbb{1}_{(H(s) \leq \bar{H})}\right]=e^{-(1-1 / \gamma)\left(r+\frac{\|\theta\|^{2}}{2 \gamma}\right)(s-t)} N\left(d_{2}\right) \\
& \mathbb{E}_{t}\left[\frac{H(s)}{H(t)} \mathbb{1}_{(H(s)>\bar{H})}\right]=e^{-r(s-t)}\left(1-N\left(d_{1}\right)\right)
\end{aligned}
$$

where $d_{1}$ and $d_{2}$ are defined in Proposition 2. The analytic expression for the optimal wealth follows by replacing 35 in the expression for financial wealth 34 . Applying Ito's lemma on the resulting expression for financial wealth and comparing the diffusion term with the dynamic budget constraint 8 gives the desired portfolio rule of Proposition 3 . 


\subsubsection{Consumption and portfolio rules of the investors with subsistence level of consumption and power utility}

The results of this appendix are derived using standard portfolio rules in continuoustime models (Merton (1971)). The utility function of the consumption insurer is defined as

$$
U(c(t), Z)= \begin{cases}-\infty, & \text { if } c(t)<Z, \\ \frac{(c(t)-Z)^{1-\gamma}}{1-\gamma}, & \text { if } c(t) \geq Z,\end{cases}
$$

The maximization problem of the consumption insurer is well defined only if initial wealth is enough to finance the reference level of consumption at any point in time, that is

$$
W_{0}>\mathbb{E}\left[\int_{0}^{\infty} H(t) Z d t\right]=\frac{Z}{r}\left(1-e^{-r T}\right)
$$

If $W(0)=\frac{Z}{r}\left(1-e^{-r T}\right)$ the problem is well posed only if $\gamma<1$. If $\gamma \geq 1$ the problem is ill posed because $U(Z, Z)=-\infty$ which implies that the only feasible consumption plan (i.e. $c(t)=Z \quad \forall t)$ cannot be optimal. Under the assumption 37, which is satisfied by the parameters in Table 1, optimal consumption and portfolio choices are obtained by the standard martingale method:

$$
\begin{aligned}
& c^{*}(t)=Z+\left(e^{\rho t} \lambda H(t)\right)^{-\frac{1}{\gamma}} \\
& W(t)=\frac{Z}{r}\left(1-e^{-r(T-t)}\right)+\lambda^{-\frac{1}{\gamma}} \frac{\left(1-e^{-\Gamma(T-t)}\right)}{\Gamma} e^{-\frac{\rho t}{\gamma}} H(t)^{-1 / \gamma} \\
& \pi(t)=\sigma^{-1} \frac{\theta}{\gamma}\left[\frac{c^{*}(t)-Z}{W(t)}\right] \frac{1-e^{-\Gamma(T-t)}}{\Gamma} \\
& \lambda^{-\frac{1}{\gamma}}=\frac{\Gamma}{1-e^{-\Gamma T}}\left(W_{0}-\frac{z}{r}\left(1-e^{-r T}\right)\right)
\end{aligned}
$$

Finally, for the investor with power utility of consumption

$$
U(c(t))=\frac{c(t)^{1-\gamma}}{1-\gamma}
$$


and the optimal consumption-portfolio choices are

$$
\begin{aligned}
& c^{*}(t)=\left(e^{\rho t} \lambda H(t)\right)^{-\frac{1}{\gamma}} \\
& \pi(t)=\sigma^{-1} \frac{\theta}{\gamma} .
\end{aligned}
$$




\section{Appendix B: Figures and tables}

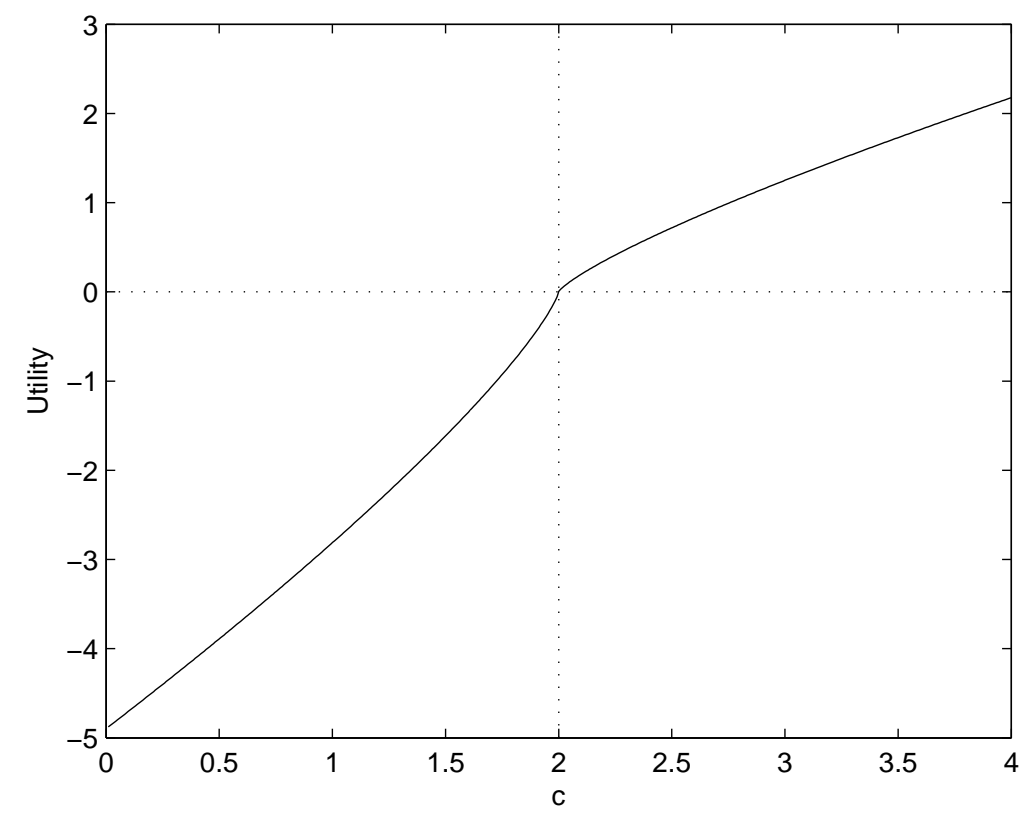

Figure 1: s-shaped utility function. The investor's utility as a function of consumption. Parameters are from Table 1. 

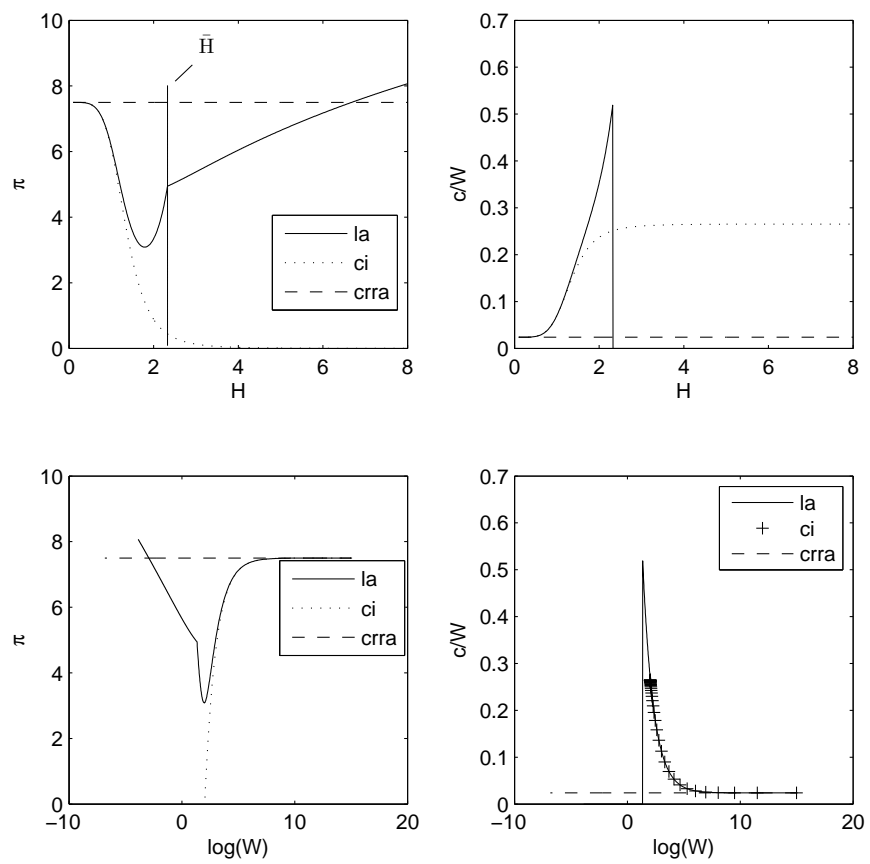

Figure 2: Consumption and portfolios. Optimal consumption and the investor's portfolio are plotted against the state-price density $H$ (upper panels), and financial wealth (lower panels). "la" stays for loss aversion and "ci" stays for consumption insurer. Parameters are from Table 1.

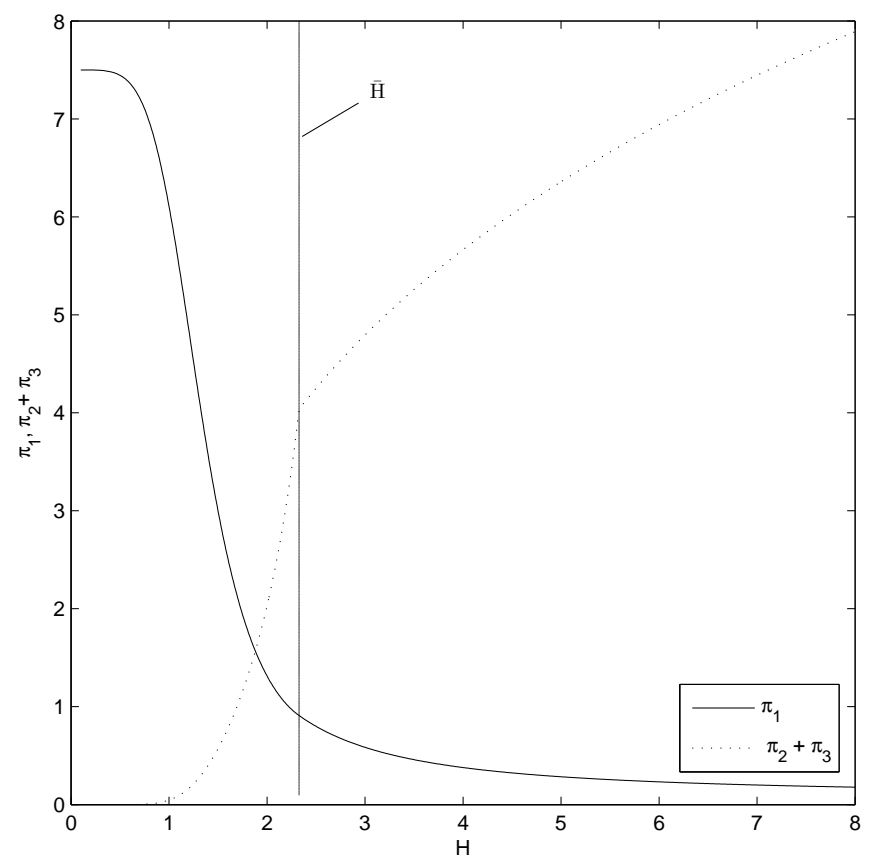

Figure 3: Optimal portfolios. The mean variance component $\left(\pi_{1}\right)$ and the gambling component $\left(\pi_{1}+\pi_{2}\right)$ of the investor's portfolio are plotted against the state-price density H. Parameters are from Table 1. 


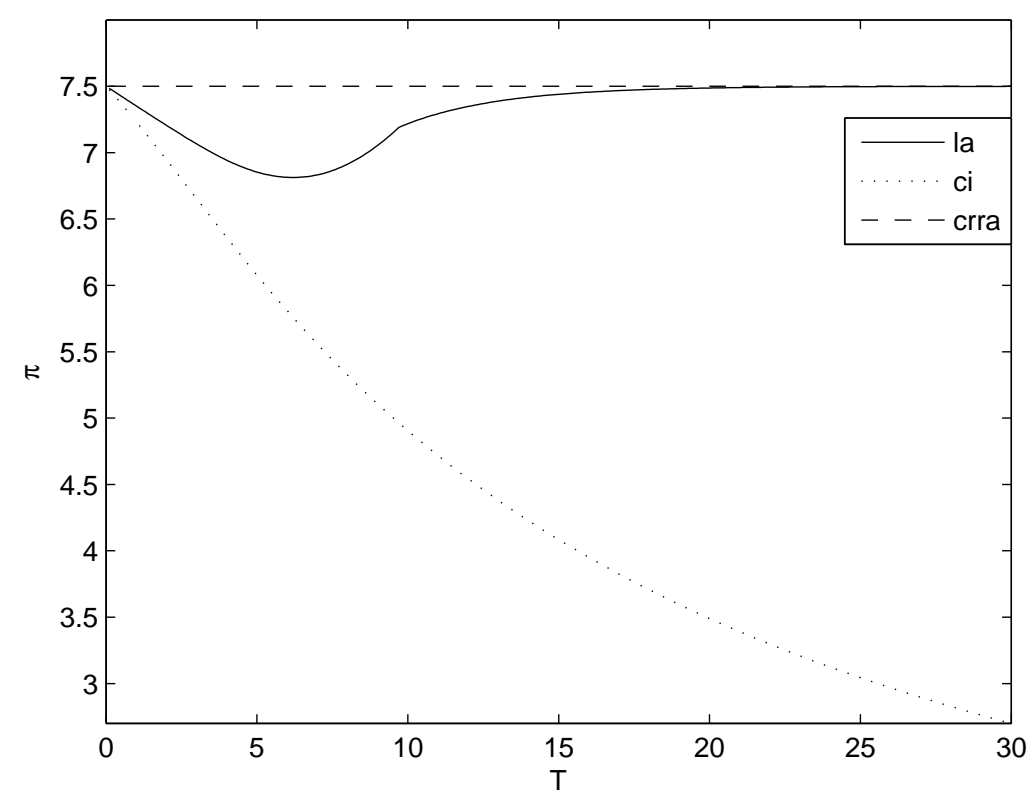

Figure 4: The effect of the investment horizon. The optimal portfolio is plotted against the investor's horizon T. "la" stays for loss aversion and "ci" stays for consumption insurer. Parameters are from Table 1.
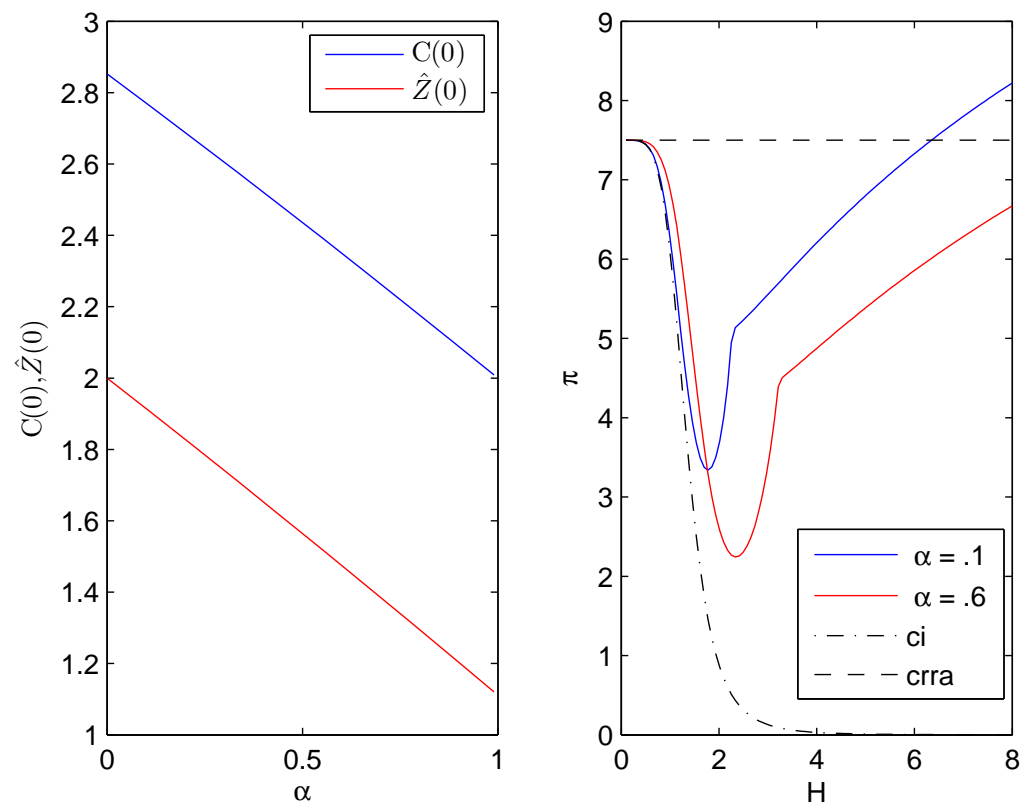

Figure 5: The effect of habit persistence. Optimal consumption as a function of habit persistence (left panel). The investor's portfolio plotted against the state-price density $H$ for different level of the habit persistence. "la" stays for loss aversion and "ci" stays for consumption insurer. Parameters are from Table 1. 

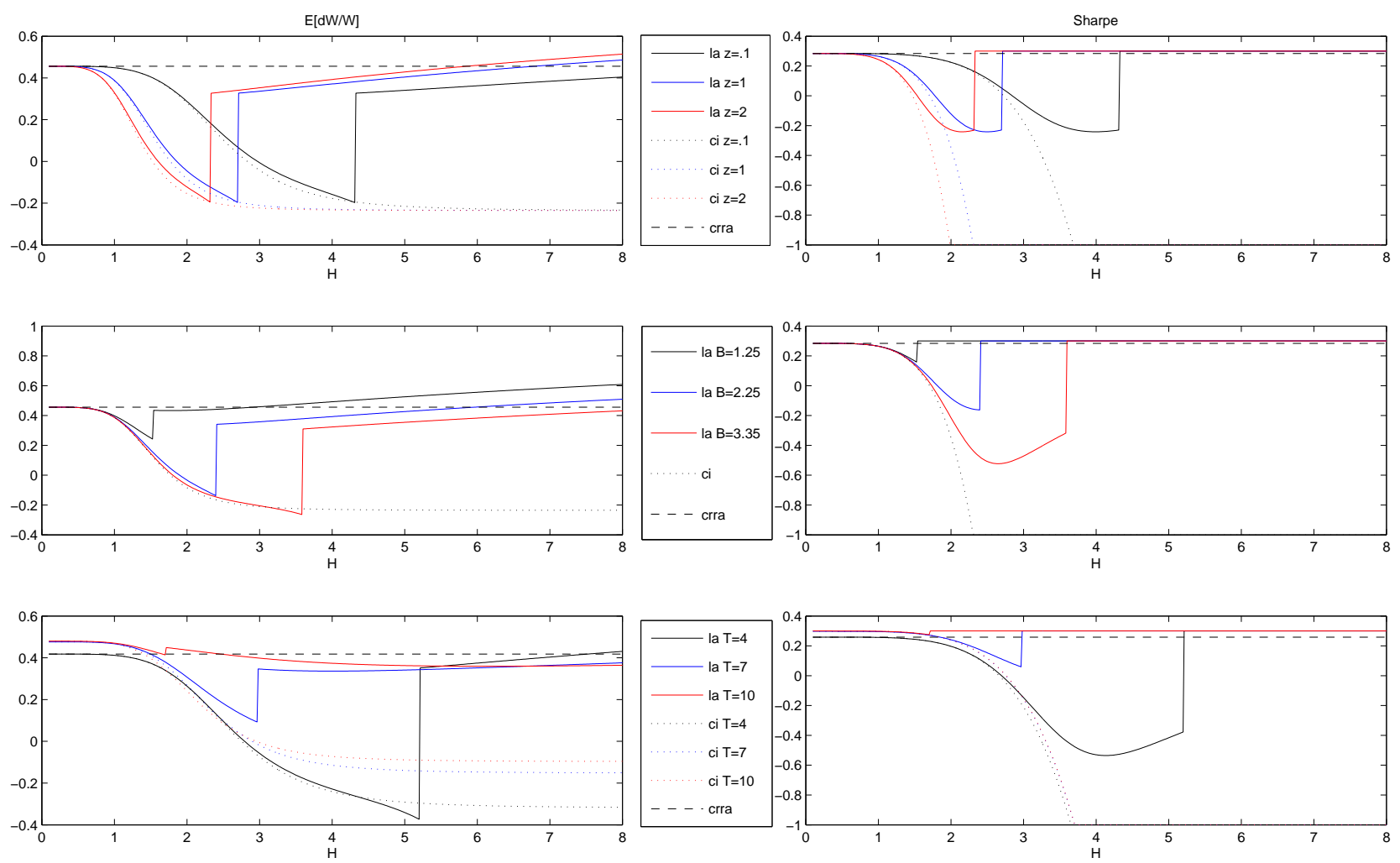

Figure 6: Portfolio performance. Performance of portfolios as a function of $H$, for different values of parameters. "la" stays for loss aversion and "ci" stays for consumption insurer. 


\begin{tabular}{ccl}
\hline \hline Symbol & Value & Description \\
\hline$\gamma$ & .2 & Curvature of utility function \\
$B$ & 2.25 & Degree of loss aversion \\
$Z_{0}$ & 2 & Initial reference level \\
$\underline{Z}$ & 0 & Subsistence level \\
$\rho$ & .02 & Subjective discount factor \\
$T$ & $0, \ldots, 30$ & Investment horizon \\
$\nu$ & $0,-.01$ & Decay rate of habits \\
$\alpha$ & $0, \ldots, 1$ & Habit persistence \\
$W_{0}$ & 100 & Initial wealth \\
$r$ & .03 & Risk free rate \\
$\theta$ & .3 & Sharpe ratio \\
$\sigma$ & .2 & Stock returns volatility \\
\hline \hline
\end{tabular}

Table 1: Model parameters: preferences, consumption and habit process. 


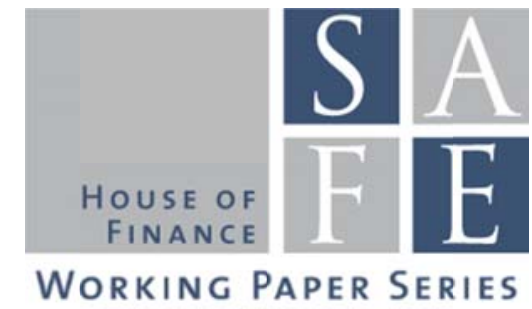

\section{Recent Issues}

No.129 Giuliano Curatola, Michael Donadelli, Patrick Grüning, Christoph Meinerding

No. 128 Giuliano Curatola

No. 127 Helmut Elsinger, Philipp SchmidtDengler, Christine Zulehner

No. 126 Carsten Bienz, Karin S. Thorburn, Uwe Walz

No. 125 Tobias H. Tröger, Uwe Walz

No. 124 Adrian Buss, Bernard Dumas, Raman Uppal, Grigory Vilkov

No. 123 Marie Lalanne, Paul Seabright

No. 122 Douglas Cumming, Uwe Walz, Jochen Werth

No. 121 Elia Berdin, Matteo Sottocornola

No. 120 Matthias Heinz, Heiner Schumacher

No.119 Michael Brennan, Holger Kraft

No. 118 Michael Donadelli, Antonio Paradiso, Max Riedel

No. 117 Marcel Bluhm

No. 116 Charles Gottlieb

No. 115 Andreas Fagereng, Charles Gottlieb, Luigi Guiso
Investment-Specific Shocks, Business Cycles, and Asset Prices

Preference Evolution and the Dynamics of Capital Markets

Competition in Treasury Auctions

Coinvestment and risk taking in private equity funds

Does Say on Pay Matter? Evidence from the German Natural Experiment

The Intended and Unintended Consequences of Financial-Market Regulations: A General Equilibrium Analysis

The Old Boy Network: The Impact of Professional Networks on Remuneration in Top Executive Jobs

The Dynamics of Entrepreneurial Careers in High-Tech Ventures: Experience, Education, and Exit

Insurance Activities and Systemic Risk

Signaling Cooperation

Leaning Against the Wind: Debt Financing in the Face of Adversity

A Quasi Real-Time Leading Indicator for the EU Industrial Production

Interbank Funding as Insurance Mechanism for (Persistent) Liquidity Shocks

On the Distributive Effects of Inflation

Asset Market Participation and Portfolio Choice over the Life-Cycle 